\title{
The effects of temperature on human compound action potentials
}

\author{
C F B OLTON, G M A WA, A N K CARTER \\ From the Department of Clinical Neurological Sciences, Victoria Hospital, \\ University of Western Ontario, London, Ontario, Canada
}

SUMMARY The upper limbs of 10 healthy subjects were cooled and then warmed over physiological temperature ranges. The compound action potentials of median digital nerves, median sensory nerve at the wrist, radial sensory nerve at the wrist, and median thenar muscle, all showed progressive reduction in latency, amplitude, duration and area during rising temperature. Our studies suggest that the sensory compound action potential changes occur predominantly because of the summated effects of reduction in the duration of the action potentials of single myelinated fibres, although disproportionate increase in the conduction velocity of larger myelinated fibres also plays a role.

A decrease in the conduction velocity and an increase in the distal latency of human peripheral nerves are well documented electrophysiological signs of neuropathy. However, when axonal degeneration predominates and segmental demyelination is minimal, these values are relatively unaltered, and the main effect is reduction in sensory nerve $^{1}$ and muscle $^{2}$ compound action potential (CAP) amplitude. Unfortunately, many factors, both technical and physiological, affect this amplitude. As a result, the coefficient of variation (the standard deviation as a percentage of the mean) of the CAP amplitude in control groups approaches $60 \% .^{34}$ Even serial tests in a single, control person show a variation of $20 \%$ to $30 \%$ for sensory CAPs using needle electrodes, ${ }^{4}$ and $15 \%$ using surface electrodes (Bolton, CF; unpublished data).

Many of the factors contributing to CAP amplitude variation in healthy persons have been defined for needle and surface electrodes. ${ }^{56} \mathrm{Limb}$ temperature may be an important variable that needs further definition. In two previous investigations of the effect of temperature on CAP ampli-

Presented in part at the XIVth Canadian Congress of Neurological Sciences, Halifax, Novia Scotia, 13-16, June 1979.

Address for reprint requests: Dr CF Bolton,Victoria Hospital Corporation, South St Campus, 375 South St, 8 Middlesex, London, Ontario N6A 4G5, Canada.

Accepted 4 February 1981 tude, needle electrodes were used for recording, and there was concern that the equivocal results may have been due to inadvertent movement of the tip of the needle during the experiment. ${ }^{57}$ Surface electrodes, although recording lower voltage potentials, remain at an almost constant distance from the nerve, tending to eliminate this source of error. We therefore used surface electrodes in studying the effect of altering limb temperature, within physiological ranges, on the latency, amplitude, duration, and area of the CAP. Antidromic and orthodromic radial sensory conduction studies were performed in 10 healthy subjects.

\section{Methods}

The subjects were 23 to 31 years old, six males and four females. In each subject the temperature of the right hand and forearm was lowered by the application of icepacks. All subsequent studies were performed at 15 minute intervals while the limb gradually warmed over approximately two hours. In some subjects, warming was enhanced by the breeze from an electric hair-dryer. Cutaneous surface temperature was monitored at the proximal part of the second digit, centre of the palm and the mid-flexor surface of the forearm immediately after each nerve conduction study.

One pair of recording and reference Beckman miniature electrodes were placed $3 \mathrm{~cm}$ apart over the superficial radial nerve at the wrist, and a second pair was placed over the median nerve at the wrist. Record- 
ing and reference Teca ring electrodes were placed $3 \mathrm{~cm}$ apart on the second digit, the recording electrode overlying the proximal crease. At each nerve conduction study, the radial nerve was stimulated in the forearm through a Disa stimulating probe, electrodes $2.5 \mathrm{~cm}$ apart. The pulses were $0.1 \mathrm{~ms}$ in duration and of supramaximal voltage. In antidromic median sensory conduction the nerve was stimulated at the wrist, just lateral to the recording electrodes, then at the elbow, and finally at the upper arm. In orthodromic median sensory conduction, the Teca ring electrodes were used for stimulation instead of recording. For median motor conduction studies, Beckman miniature recording and reference electrodes were placed at standard positions over the thenar eminence and proximal thumb. The thenar CAP was recorded simultaneously with the antidromic sensory CAP on a separate oscilloscope channel from stimuli delivered to the median nerve at wrist, elbow and upper arm. The sites of stimulating and recording electrodes were constant during the experiment. Resistance of the electrodes was measured at intervals during the experiment. Teca ring electrodes had to be reapplied at times because the electrode paste dried; this manoeuvre prevented electrode resistance from rising. Tissue resistance was not measured, but Ludin and Beyeler ${ }^{7}$ showed tissue resistance was unchanged during a similar experiment.

Polaroid pictures of the oscilloscope traces were magnified five times for accurate measurement. Latency was measured as the time from stimulus artifact to beginning of the negative phase of the CAP, and duration was the time of the negative phase. Because of the possible interference of the late positive phase of the antidromic sensory CAP by muscle CAP, the peak to peak amplitude and the total duration of the CAP were not measured. The rise time was not studied since it was often too brief to be measured accurately. Amplitude was measured as the height of the negative phase. The statistical calculations were performed on a Tektronix 451 computer, using Plot 50 statistics, volume 1, software. The area of the negative phase was computed using the Tektronix computer, oscilloscope and graphics tablet. Proximal and distal unipolar, and bipolar recording arrangements were set up $^{5}$ in two subjects. Supramaximal stimuli were delivered to the median nerve at wrist. CAPs were recorded via Teca ring electrodes, placed $3.0 \mathrm{~cm}$ apart on the third digit, and proximal electrode overlying the proximal crease. The reference electrode for the monopolar recordings was a silver strip placed along the length of the fifth digit and hypothenar eminence. By this method, it was possible to compare CAPs recorded from proximal and distal monopolar, and bipolar recording arrangements using the same stimuli.

Equipment used included a Disa 14E11 stimulator; low noise integrated circuit amplifiers with high input impedance and a frequency range set of 20 to $5,000 \mathrm{~Hz}$; and a Hewlett-Packard 141B oscilloscope. With thlis equipment and technique, all CAPs were of large enough voltage that averaging was unnecessary.

\section{Results}

The mean range of cutaneous temperature rise during warming was less proximally than distally, the expected physiological temperature gradient. However, there was considerable variation between individuals in the range and rate of temperature rise that was induced by this experiment (table 1), likely reflecting differences in physiological adaptation to cooling and warming.

We found strong correlations between the various nerve conduction measurements and each of the three sites of cutaneous temperature monitoring, but the best correlations were with the cutaneous temperature site that was nearest to the length of nerve over which conduction velocity was measured (table 2), or to the recording electrode from which the CAP was recorded and its various measurements determined (table 3 ). The change of the nerve conduction measurements with increasing temperature varied considerably between subjects, but at least one subject showed statistically significant changes for each measurement (example in fig 1) the only exceptions being the CAP amplitudes of the median sensory nerve at the wrist (table 3).

Conduction velocity rose at a mean rate of between 1.64 to $2.31 \mathrm{~m} /{ }^{\circ} \mathrm{C}$ for the motor and sensory nerves (table 2 ).

Table 1 Cutaneous temperature rise during warming of upper limb in 10 healthy subjects

\begin{tabular}{llll}
\hline & $\begin{array}{l}\text { Mean low } \\
(\text { range }){ }^{\circ} \mathrm{C}\end{array}$ & $\begin{array}{l}\text { Mean high } \\
(\text { range })\end{array}$ & $\begin{array}{l}\text { Mean } \\
\text { difference }\end{array}$ \\
\hline Finger & $22 \cdot 5(19 \cdot 7-27 \cdot 0)$ & $33 \cdot 6(30 \cdot 5-36 \cdot 2)$ & $11 \cdot 1$ \\
Palm & $25 \cdot 3(22 \cdot 8-28 \cdot 0)$ & $32 \cdot 1(29 \cdot 5-34 \cdot 5)$ & $6 \cdot 8$ \\
Forearm & $26.9(25 \cdot 1-29 \cdot 5)$ & $30 \cdot 9(28 \cdot 3-34 \cdot 0)$ & $4 \cdot 0$ \\
\hline
\end{tabular}

Table 2 Absolute change of conduction velocities with cutaneous temperature

\begin{tabular}{lll}
\hline & $b\left(\mathrm{~m} / \mathrm{s} /{ }^{\circ} \mathrm{C}\right)$ & $r^{2}$ \\
\hline $\begin{array}{l}\text { Median sensory } \\
\text { antidromic }\end{array}$ & & \\
$\begin{array}{c}\text { Elbow-wrist* } \\
\text { Wrist-digit } \dagger\end{array}$ & $+1.64(0.46-3.74)$ & $0.34(0.05-0.63)$ \\
$\begin{array}{l}\text { Median sensory } \\
\text { orthodromic } \\
\quad \text { Digit-wrist } \dagger\end{array}$ & $+2.31(1.21-3.41)$ & $0.76(0.50-1.00)$ \\
$\begin{array}{l}\text { Median motor } \\
\text { orthodromic } \\
\text { Elbow-wrist* }\end{array}$ & $+1.47(0.00-3.66)$ & $0.45(0.21-0.69)$ \\
\hline
\end{tabular}

Linear regression values (mean (range)) in 10 healthy subjects; b-balue in equation $y=a+b x ; r^{2}-$ coefficient of determination; ${ }^{*}-$ correlated with forearm temp; $\dagger$-with palm temp. 


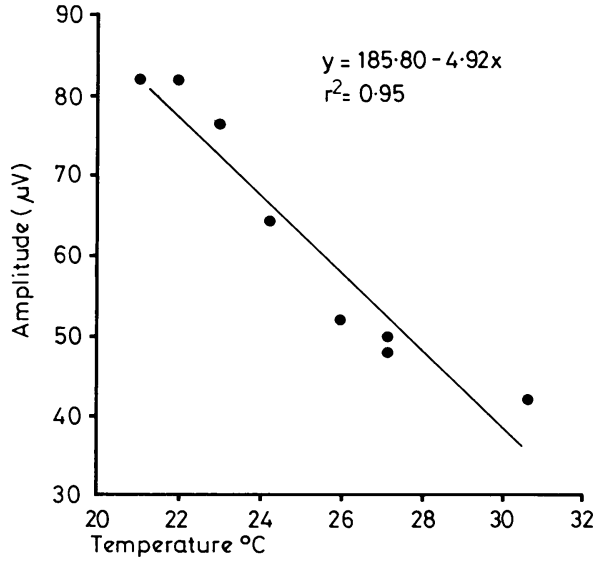

Fig 1 The relationship between the amplitude of the $C A P$ of the median digital nerves of the index finger and rising temperature of the cutaneous surface of that digit in a healthy subject.

The CAP distal latencies of median digital nerves (antidromic) and the median sensory nerve at the wrist (orthodromic) showed a decrease which was similar, but not identical (table 3). However, when the latency of the CAP of the median digital nerves was correlated with palm temperature, instead of digit temperature as shown in table 3 , the rate of decrease of the latency was identical to that of the CAP of the median sensory nerve at the wrist. Thus, the absolute values for latency in both antidromic and orthodromic median sensory conduction were the same, confirming Buchthal and Rosenfalk's ${ }^{5}$ earlier finding. This result is to be expected since the sites and distances between stimulating and recording electrodes are the same for each subject, except they are interchanged for the respective antidromic and orthodromic conduction.

The CAP distal latencies of the radial sensory nerve at the wrist (antidromic) and the thenar muscle (orthodromic) decreased to a similar degree, and both were approximately twice the degree of decrease of orthodromic median nerve conduction. The reason for these observations is not apparent. The greater decrease of thenar muscle CAP latency, compared to median digital CAP latency, was not due to the negative phase of the median digital nerve CAP being interfered with by muscle CAP. We would have observed such an interference, since we recorded both CAPs simultaneously on separate oscilloscope channels, using the same stimulus.

The CAP amplitudes of the median digital nerves and the radial sensory nerve at the wrist both fell markedly, but the fall was much less for CAP amplitude of the median sensory nerve at the wrist and thenar muscle. The CAP duration change was greatest for the thenar muscle, and much less for the three sensory nerves.

Since the combined effect of increase in temperature was a reduction in both CAP amplitude and duration, changes in CAP area were marked. The CAP area decreased approximately $10 \% /{ }^{\circ} \mathrm{C}$ for radial sensory nerve, $5 \%$ for median digital nerves, and $3 \%$ for the median sensory nerve at the wrist and median thenar muscle (table 3 ).

In antidromic sensory conduction, the CAPs of median digital nerves were recorded on stimulation of the median nerve at the wrist, elbow and upper arm (fig 2). (In orthodromic median sensory conduction, CAPs cannot usually be recorded proximal to the wrist using surface electrodes, without utilising averaging techniques. In radial nerve antidromic sensory conduction, we arbi-

Table 3 Change (mean range) of CAP measurements with cutaneous temperature

\begin{tabular}{|c|c|c|c|c|c|c|c|c|}
\hline \multirow[t]{2}{*}{$C A P$} & \multicolumn{2}{|c|}{ Distal latency } & \multicolumn{2}{|l|}{ Amplitude } & \multicolumn{2}{|l|}{ Duration } & \multicolumn{2}{|l|}{ Area } \\
\hline & $b\left(\left.m s\right|^{\circ} C\right)$ & $r^{2}$ & $b\left(u V /{ }^{\circ} C\right)$ & $r^{2}$ & $b\left(m s /{ }^{\circ} C\right)$ & $r^{2}$ & $b\left(\% /{ }^{\circ} \mathrm{C}\right)$ & $r^{2}$ \\
\hline $\begin{array}{l}\text { Median digital } \\
\text { nerves }+ \\
\text { (antidromic) }\end{array}$ & $\begin{array}{l}-0.07 \\
(0.02-0 \cdot 16)\end{array}$ & $\begin{array}{l}0.84 \\
(0.69-0.99)\end{array}$ & $\begin{array}{l}-1 \cdot 90 \\
(0 \cdot 52-4 \cdot 92)\end{array}$ & $\begin{array}{l}0.79 \\
(0 \cdot 56-1 \cdot 00)\end{array}$ & $\begin{array}{l}-0.06 \\
(0.02-0.12)\end{array}$ & $\begin{array}{l}0 \cdot 78 \\
(0 \cdot 55-1 \cdot 00)\end{array}$ & $\begin{array}{l}-5 \cdot 5 \\
(3 \cdot 5-10 \cdot 0)\end{array}$ & $\begin{array}{l}0.83 \\
(0.70-0.96\end{array}$ \\
\hline $\begin{array}{l}\text { Median sensory } \\
\text { nerve at wrist } \dagger \\
\text { (orthodromic) }\end{array}$ & $\begin{array}{l}-0 \cdot 11 \\
(0 \cdot 05-0 \cdot 15)\end{array}$ & $\begin{array}{l}0 \cdot 76 \\
(0 \cdot 50-1 \cdot 00)\end{array}$ & $\begin{array}{l}-0.04 \\
(0.00-0.09)\end{array}$ & $\begin{array}{l}0.33 \\
(0.08-0.58)\end{array}$ & $\begin{array}{l}-0.05 \\
(0.01-0.09)\end{array}$ & $\begin{array}{l}0.67 \\
(0.44-0.90)\end{array}$ & $\begin{array}{l}-3 \cdot 1 \\
(0 \cdot 2-7 \cdot 3)\end{array}$ & $\begin{array}{l}0.39 \\
(0 \cdot 10-0 \cdot 68)\end{array}$ \\
\hline $\begin{array}{l}\text { Radial sensory } \\
\text { nerve at wrist } \dagger \\
\text { (antidromic) }\end{array}$ & $\begin{array}{l}-0 \cdot 21 \\
(0 \cdot 10-0 \cdot 32)\end{array}$ & $\begin{array}{l}0.78 \\
(0.66-0.90)\end{array}$ & $\begin{array}{l}-1 \cdot 76 \\
(0 \cdot 49-3 \cdot 03)\end{array}$ & $\begin{array}{l}0.55 \\
(0 \cdot 28-0 \cdot 82)\end{array}$ & $\begin{array}{l}-0 \cdot 10 \\
(0 \cdot 00-0 \cdot 21)\end{array}$ & $\begin{array}{l}0.38 \\
(0.14-0.62)\end{array}$ & $\begin{array}{l}-10 \cdot 78 \\
(0 \cdot 1-20 \cdot 0)\end{array}$ & $\begin{array}{l}0.51 \\
(0.02-0.82)\end{array}$ \\
\hline $\begin{array}{l}\text { Median thenar } \\
\text { muscle } \dagger\end{array}$ & $\begin{array}{l}-0.26 \\
(0.08-0.52)\end{array}$ & $\begin{array}{l}0.84 \\
(0.70-0.98)\end{array}$ & $\begin{array}{l}b\left(\left.m V\right|^{\circ} C\right) \\
-0.24 \\
(0.00-0.55)\end{array}$ & $\begin{array}{l}0.46 \\
(0.08-0.84)\end{array}$ & $\begin{array}{l}-0.25 \\
(0 \cdot 08-0 \cdot 71)\end{array}$ & $\begin{array}{l}0.77 \\
(0.62-0.92)\end{array}$ & $\begin{array}{l}-2 \cdot 7 \\
(0 \cdot 2-5 \cdot 6)\end{array}$ & $\begin{array}{l}0.62 \\
(0.35-0.89)\end{array}$ \\
\hline
\end{tabular}

Designations as in table $2 ; \ddagger-$ Correlated with digit temp. 
(a)

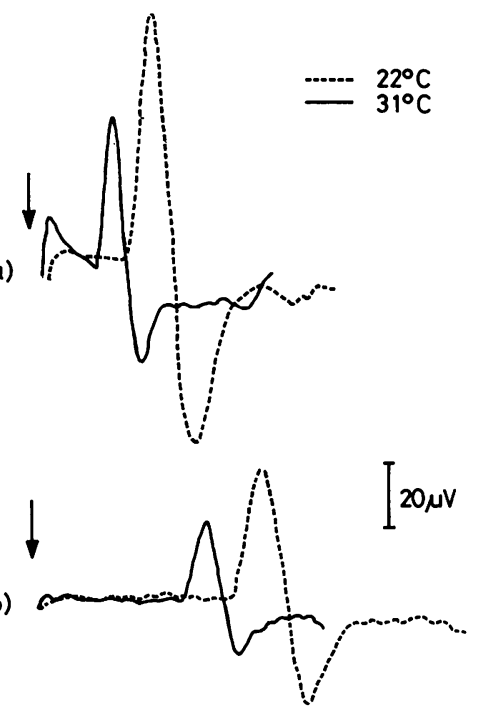

(c)

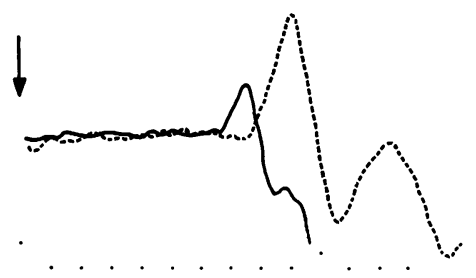

Fig 2 The CAPs of median digital nerves from stimulation at wrist (a), elbow (b) and upper arm (c) at cool and warm finger temperatures. Note the decrease in the amplitude, duration and area of $C A$ on more proximal stimulation, independent of temperature, but the further decrease in these features at higher temperature. An analysis of the results of this experiment in all 10 subjects is shown in fig 3. (Dots in lower scale are at $1 \mathrm{~ms}$ intervals.)

trarily decided to stimulate at only one site.) The CAP of median digital nerves normally becomes dispersed, of lower amplitude and greater duration, on more proximal stimulation (fig 2), owing to the differing conduction rates of larger myelinated fibres. We compared the $\%$ change per ${ }^{\circ} \mathrm{C}$ in these CAP measurements with increasing distance at the three sites of stimulation (fig 3). Area, amplitude and duration all showed a greater $\%$ decrease on more proximal stimulation (in that order), suggesting that rising temperature caused a relatively greater increase in conduction velocity of larger myelinated fibres, although this relative increase was small.

The size and shape of the CAP recorded with bipolar surface electrodes is due partly to the

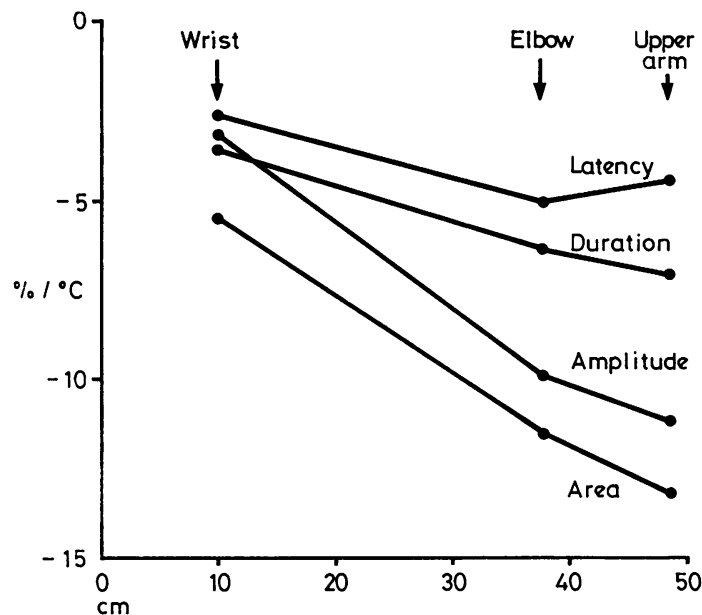

Fig 3 The relationship between the effects of rising temperature on median digital nerve $C A P$ measurements and increasing distance between stimulating and recording electrodes for the 10 subjects. $\% /{ }^{\circ} \mathrm{C}$ for each measurement was determined by converting the absolute value of $b$ in the equation $y=a+b x$ for each subject to $a \%$ and then calculating the mean $\%$ for the 10 subjects; $\downarrow$ designate sites of stimulation of median nerve.

voltage difference between reference and recording electrodes induced by the successive arrival times of the CAP at each of these electrodes. ${ }^{5}$ To determine if the greater rate of conduction of the larger myelinated fibres induced by the temperature rise affected this voltage difference, we recorded the CAP of median digital nerves on antidromic stimulation by both bipolar and monopolar techniques in two subjects. The CAP from each technique showed similar changes in size and shape with increase in temperature (fig 4), showing that latency changes between the electrodes induced by the increased conduction rate of larger myelinated fibres was insignificant.

\section{Discussion}

Our study has shown that the various CAP measurements are remarkably sensitive to temperature change, and such change must be taken into account if these measurements are to be accurately interpreted in clinical electrophysiology. However, we emphasise that we documented only temperature effects within physiological ranges in the upper limb of healthy young adults; these results may not apply to nerves of older persons, nor to diseased nerve. 


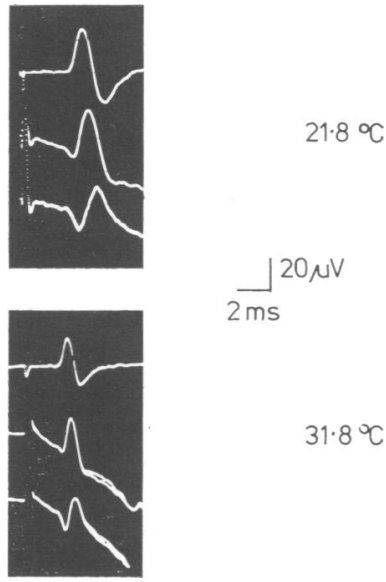

Fig 4 Recording of monopolar and bipolar action potentials in one subject at cool and warm temperatures. At each temperature, the upper trace shows the bipolar, the middle trace the proximal monopolar, and the lower trace the distal monopolar, action potentials; all three action potentials were recorded at the middle finger from the same supramaximal stimulus to the median nerve at the wrist (see Methods). Note the reductions in latency, amplitude and duration are similar at higher

temperature for bipolar and monopolar recordings.

We monitored temperature from the cutaneous surface. The superficial radial and median digital nerves lie superficial to the deep fascia, close to the cutaneous surface. Temperature at this site is governed by the sweat and blood flow regulated by cutaneous sympathetic fibres. ${ }^{8}$ As a result, the surface cutaneous temperature is only approximately $1{ }^{\circ} \mathrm{C}$ less than the tissue temperature near these nerves. ${ }^{49}$ However, the median nerve proximal to the digits lies beneath the deep fascia and, in this part of its course, probably does not follow as closely the cutaneous surface temperature. Nonetheless, there was, in individual subjects, an excellent correlation between cutaneous surface temperature at each of the three sites and the various nerve conduction measurements. The excellent correlation included conduction velocities from the deeper segments of the median nerve, our results being similar to other studies in which subcutaneous or intramuscular temperature was monitored. ${ }^{510-12}$ Moreover, we found that the distal latency of the thenar CAP changed $0.26 \mathrm{~ms} /{ }^{\circ} \mathrm{C}$, a rate similar to that recorded by Carpendale, who recorded temperature from within the thenar muscle. ${ }^{13}$
Striking changes in CAP latency, amplitude, duration and area occurred, all of these values showing a negative linear correlation with temperature, that is all decreased as temperature rose. The magnitude of these changes varied considerably between individuals. However, the correlation for each of these values was statistically significant in at least one subject, the only exceptions being the CAP amplitudes of the median sensory nerve at the wrist.

The amplitude fall with rise in temperature for the median sensory nerve at the wrist recorded orthodromically was small, and similar to that reported by Ludin and Beyeler ${ }^{7}$ for the temperature range $26-36^{\circ} \mathrm{C}$. They used needle electrodes for recording and found a puzzling rise in amplitude as temperature increased from $22-26^{\circ} \mathrm{C}$. In an earlier study, Buchthal and Rosenfalk ${ }^{5}$ found no consistent change in this amplitude, a result they attributed to inadvertent movement of the needle electrode during the experiment. The somewhat equivocal change in the amplitude of the median CAP at the wrist recorded orthodromically contrasts with the marked fall in CAP amplitude in both the median digital nerves and the radial sensory nerve at the wrist recorded antidromically. Hlavova et al $^{14}$ had previously noted this contrasting result between median nerve orthodromic and antidromic conduction. The reasons are open to speculation: (1) there may be differences between orthodromic and antidromic conduction that have yet to be defined, (2) the nerves of the cutaneous and subcutaneous tissue may be particularly sensitive to temperature change. They lie beneath the recording electrodes and may have been activated in median and radial nerve antidromic conduction and such activation may have contributed to the CAP, whereas nerves of this tissue beneath the electrode at the wrist in orthodromic median conduction arise from the palmar cutaneous branch of the median nerve and were presumably not activated, (3) the vasodilating response with warming occurs predominantly in cutaneous and subcutaneous tissues superficial to the deep fascia. The median digital and superficial radial nerves are in this superficial location and would be more subject to such a response than the median nerve at the wrist which lies beneath the deep fascia. The vasodilating response would increase vascular and interstitial fluid, tending to move the recording electrode further from the nerve; it might also increase the volume within the endoneural space, tending to decrease the density of nerve fibres within this space. Greater distance of recording electrode to nerve, and decreased density of nerve 
fibres, are both known to decrease the amplitude of CAPs. ${ }^{515}$ The relevance of these various factors requires further investigation.

The results of animal experiments (if they apply to man) suggest the main mechanisms of the sensory CAP changes. Although Tasaki and Fugita $^{16}$ reported a rise of the action potential of single axons of the toad recorded extracellularly, the weight of evidence favours a fall in amplitude with increase in temperature. Such a fall occurred in the intracellularly recorded action potential of the squid axon ${ }^{17} 18$ and in the extracellularly recorded action potential of frog myelinated fibres ${ }^{19}$ and single myelinated fibre of rat ventral root. ${ }^{20}$ However, a decrease in the duration of these action potentials has been a more consistent observation and is more marked than the fall in amplitude (fig 5). Temperature also affects the rate of conduction of myelinated fibres, the larger myelinated fibres of the cat cervical vagus nerve conducting more rapidly with increase in temperature than the smaller diameter fibres. ${ }^{21} \mathrm{~A}$ total conduction block will occur in myelinated fibres only at very high or very low temperature. ${ }^{21-23}$ Thus, human CAP changes during physiological temperature rise probably occur by two main mechanisms: (1) the action potential of a single myelinated nerve fibre is only mildly reduced in amplitude but considerably reduced in duration, the summated effect on the CAP from a nerve trunk being a reduction
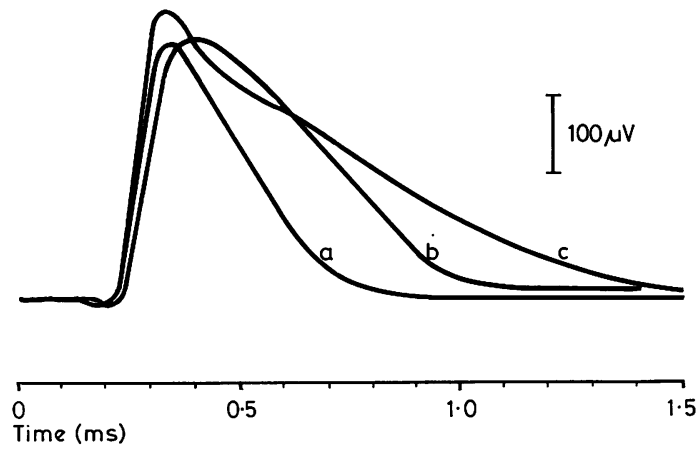

Fig 5 Action potentials recorded from single myelinated fibres of rat ventral root at $37^{\circ} \mathrm{C}($ a), at $31^{\circ} \mathrm{C}(b)$, and at $37^{\circ} \mathrm{C}$ after exposure to scorpion venom for $30 \mathrm{~s}(\mathrm{c})$. Note marked reduction of duration, and mild reduction in amplitude with higher temperature (figure taken from Bostock $H$, Sherratt RM, and Sears, TA: Overcoming conduction failure in demyelinated nerve fibres by prolonged action potentials. Reprinted by permission from Nature, Vol. 274, No. 5669, 385-7, Copyright ( (C) 1978 Macmillan Journals Limited). in both amplitude and duration; and (2) the larger diameter myelinated fibres conduct at a disproportionately greater rate, causing a dispersion of the CAP, that is a further reduction in amplitude but an increase in duration. The first mechanism is likely to be the predominant one. It overcomes the second mechanism, resulting in an overall decrease in duration of the CAP. The second mechanism can be examined in isolation by noting the effect on the CAP of stimulating the nerve at increasing distances from the recording electrodes, since, according to the all or none law, the action potential of single myelinated fibres induced in this way should remain constant in size and shape when the recording electrode is stationary. Without temperature change, this results in a progressive dispersion of the CAP, a reduction in the amplitude and an increase in the duration of the CAP, due to greater rates of conduction by larger myelinated fibres (fig 2); the reduction in area and relatively less increase in duration likely occurs because the CAP becomes so dispersed that electrical activity from some of the fibres is unrecordable. With rising temperature, there was a further reduction in area, amplitude and, to a lesser extent, duration on more proximal stimulation (figs 2,4 ), indicating more rapid conduction in larger myelinated fibres relative to smaller myelinated fibres tended to disperse the CAP. However, this effect was mild, suggesting again that the effect of temperature on the action potential of single myelinated fibres is predominant, the summated effect strongly influencing CAP area, amplitude and duration.

Interpretation of the changes in thenar muscle CAP are particularly complicated and involve not only a consideration of neural events, but of events at the neuromuscular junction and muscle membrane; such considerations are beyond the scope of this discussion. Briefly, however, a mild fall in the amplitude of the thenar muscle CAP with rising temperature occurred in a few subjects in our study. Ricker $e t a l^{24}$ showed a greater fall, which they attributed to changes in muscle cell membrane. They also showed that the twitch force increased, presumably a temperature effect on the contractile apparatus. These investigators noted muscle CAP duration decreased, but did not quantify the decrease. We found that duration changed more consistently than amplitude, at $-0.25 \mathrm{~ms} /{ }^{\circ} \mathrm{C}$.

We thank Miss Betsy Toth, secretary, for typing the manuscript, $\mathrm{Mr}$ Mike Clark, electronics technician, for constructing EMG equipment, and 
personnel in the Department for volunteering as healthy subjects.

\section{References}

1 Buchthal F, Behse F. Peroneal muscular atrophy (PMA) and related disorders. 1. Clinical manifestations as related to biopsy findings, nerve conduction and electromyography. Brain 1977; 100: 41-66.

2 Bolton CF, Gilbert JJ, Girvin JP, Hahn AF. Nerve and muscle biopsy. Correlation of electrophysiology and morphology in polyneuropathy. Neurology (Minneap) 1979; 28:354-62.

3 Bolton CF. Electrophysiological changes in uremic neuropathy following successful renal transplantation. Neurology (Minneap) 1976; 26:152-61.

4 Rosenfalk A. Early recognition of nerve disorders by near-nerve recording of sensory action potentials. Muscle and Nerve 1978; 1:360-7.

5 Buchthal F, Rosenfalk A. Evoked action potentials and conduction velocity in human sensory nerves. Brain Res 1966; 3:1-122.

6 Bolton CF, Carter K. Human sensory nerve compound action potential amplitude. Variation with sex and finger circumference. J Neurol Neurosurg Psychiatry (in press).

7 Ludin HP, Beyeler F. Temperature dependence of normal sensory nerve action potentials. $J$ Neurol 1977; 216:173-80.

8 Valbo AB, Hagbarth HE, Torebjork HE, Wallin BG. Somatosensory, proprioceptive, and sympathetic activity in human peripheral nerves. Physiol Rev 1979; 59:919-57.

9 Abramson DI, Luke SWC, Rickert BL, Talso JF, Lee SW. Latency changes in distal median nerve produced by alterations in ambient temperatures. J Appl Physiol 1969; 27:795-803.

10 DeJesus PV, Hansmanowa-Petruscewicz I, Barchi RL. The effect of cold on nerve conduction of human slow and fast nerve fibers. Neurology (Minneap), 1973; 23:1182-9.

11 Lowitzsch K, Hopf HC Galland J. Changes of sensory conduction velocity and refractory periods with decreasing tissue temperature in man. $J$ Neurol 1977; 216:181-8.

12 Henriksen JD. Conduction velocity of motor nerves in normal subjects and in patients with neuromuscular disorders. Thesis. Minneapolis, 1956.

13 Carpendale MTF. Conduction time in the terminal portion of the motor fibers of the ulnar, median and peroneal nerves in healthy subjects and in patients with neuropathy. Thesis. University of Minnesota Graduate School, 1956.

14 Hlavova A, Abramson DI, Rickert BL, Talso JF. Temperature effects on duration and amplitude of distal median nerve action potential. J Appl Physiol 1970; 28:808-12.

15 Lambert EH, Dyck PJ. Compound action potentials of sural nerve in vitro in peripheral neuropathy. In: Dyck, PJ, Thomas PK, Lambert EH, eds. Peripheral Neuropathy. Philadelphia: WB Saunders Co, 1975; I:241.

16 Tasaki I, Fugita M. Action currents of single nerve fibers as modified by temperature changes. J Neurophysiol 1948; 11:311-5.

17 Hodgkin AL, Katz B. The effect of temperature in the electrical activity of the giant axon of the squid. J Physiol (Lond) 1949; 109:240-9.

18 Huxley AF. Ion movements during nerve activity. Ann NY Acad Sci, 1959; 81:221-46.

19 Schaepfle GM, Erlanger J. The action of temperature on the excitability, spike height and configuration, and the refractory period observed in the responses of single medullated nerve fibers. Am J Physiol 1941; 134:694-704.

20 Bostock H, Sherratt RM, Sears TA. Overcoming conduction failure in demyelinated nerve fibers by prolonging action potentials. Nature 1978; 274:385-7.

21 Li CL, Mathews G, Bok FA. Effect of temperature on the response of cervical vagus nerve. Exp Neurol 1977; 55:709-18.

22 Rasminsky M. The effects of temperature on conduction in demyelinated single nerve fibers. Arch Neurol 1973; 28:287-92.

23 Low PA, McLeod JG. Refractory period, conduction of trains of impulses, and effect of temperature on conduction in chronic hypertrophic neuropathy: electrophysiological studies on the Trembler mouse. J Neurol Neurosurg Psychiatry 1977; 40:434-47.

24 Ricker K, Hertel G, Stadieck G. Increased voltage of the muscle action potential of normal subjects after cooling. $J$ Neurol 1977; 216:33-8. 